\title{
Ginsenoside Rg1 Protects Cardiomyocytes Against Hypoxia/Reoxygenation Injury via Activation of Nrf2/HO-1 Signaling and Inhibition of JNK
}

\author{
Qianhui Lia Yin Xiang ${ }^{a} \quad$ Yu Chen ${ }^{b} \quad$ Yong Tang $^{a} \quad$ Yachen Zhang $^{a}$ \\ aDepartment of Cardiology, Xinhua Hospital, Shanghai Jiaotong University School of Medicine, \\ Shanghai, 'bepartment of Cardiology, Ninth People's Hospital, Shanghai Jiaotong University School of \\ Medicine, Shanghai, China
}

\section{Key Words}

Ginsenoside Rg1 Cardiomyocyte Hypoxia/reoxygenation Nuclear factor erythroid 2-related factor 2 Heme oxygenase-1

\begin{abstract}
Background/Aims: Excessive reactive oxygen species (ROS) disturb the physiology of H9c2 cells, which is regarded as a major cause of H9c2 cardiomyocyte apoptosis. Ginsenoside Rg1 is the main active extract of ginseng, which has important antioxidant properties in various cell models. This project investigated the role of ginsenoside $\mathrm{Rg} 1$ in hypoxia/reoxygenation $(\mathrm{H} / \mathrm{R})$-induced oxidative stress injury in cultured H9c2 cells to reveal the underlying signaling pathways. Methods: H9c2 cells were pretreated with ginsenoside Rg1 for $12 \mathrm{~h}$ before exposure to $\mathrm{H} / \mathrm{R}$. In the absence or presence of Nrf2siRNA, HO-1 inhibitor (ZnPP-IX), and inhibitors of the MAPK pathway (SB203580, PD98059, SP600125), H9c2 cells were subjected to $\mathrm{H} / \mathrm{R}$ with $\mathrm{Rg} 1$ treatment. The effects and mechanisms of $\mathrm{H} / \mathrm{R}$-induced cardiomyocyte injury were measured. Results: Ginsenoside Rg1 treatment suppressed H/R-induced apoptosis and caspase-3 activation. Ginsenoside Rg1 treatment decreased ROS production and mitochondrial membrane depolarization by elevating the intracellular antioxidant capacity of superoxide dismutase (SOD), glutathione peroxidase (GSH-Px), and reduced glutathione (GSH). Furthermore, ginsenoside Rg1 stimulation appeared to result in nuclear translocation of NF-E2-related factor 2 (Nrf2), along with enhanced expression of the downstream target gene heme oxygenase-1 (HO-1) in a dose-dependent manner. However, ginsenoside Rg1-mediated cardioprotection was abolished by Nrf2-siRNA and HO-1 inhibitor. H/R treatment increased the levels of phosphorylated c-Jun N-terminal kinases ( $\mathrm{p}$-JNK), which was dramatically attenuated by ginsenoside Rg1 and SP600125 (a specific JNK inhibitor). Conclusion: These observations indicate that ginsenoside $\mathrm{Rg} 1$ activates the $\mathrm{Nrf2} / \mathrm{HO}-1$ axis and inhibits the JNK pathway in $\mathrm{H} 9 \mathrm{c} 2$ cells to protect against oxidative stress.




\section{Introduction}

Ischemic heart disease is the leading cause of death all over the world [1]. Although restoration of coronary blood flow by drug or mechanical interventions can rescue viable myocardium, reperfusion may lead to sustained and even irreversible tissue damage, which ultimately causes myocardial cell apoptosis and necrosis [2]. This phenomenon is referred to as ischemia/reperfusion (I/R) injury, which decreases the therapeutic advantage of such interventions [3]. In fact, reperfusion initiates multiple events within the first few minutes after restoration of coronary blood flow, and the complex processes involve numerous signaling pathways and molecular players [4] as a result of oxidative stress [5] and inflammation [6]. Redox balance plays the key role in heart function and survival of cardiomyocytes. A large number of studies have revealed that reactive oxygen species (ROS), which are generated by ischemic cardiomyocytes and inflammatory cells at reperfusion [7], may activate many molecular cascades of inflammation and apoptosis $[1,8]$. Excessive ROS accumulation gives rise to an imbalance between oxidant and antioxidant systems [9]. ROS-induced oxidative stress is responsible for the pathophysiology of cardiac reperfusion damage following acute myocardial ischemia. Paradoxically, an appropriate level of ROS has been considered an essential component of cardioprotective molecules. Despite the complicated role of ROS, administration of a variety of antioxidants has still attracted substantial attention from researchers [9].

Many studies have reported nuclear factor erythroid 2-related factor 2 (Nrf2) as a transcription factor in cardiovascular diseases [10] that are relevant to oxidative stress. Nrf2 plays a pivotal role in cellular defense against oxidative stress and toxicological response by upregulating the expression of phase II detoxifying enzymes [11]. Interruption of this pathway can bring about a major imbalance in cellular redox homeostasis [12]. Nrf2 belongs to the basic leucine zipper transcription activator family. Under unstressed circumstances, Nrf2 is anchored to cytoplasmic actin by Kelch-like ECH-associated protein 1 (Keap1), and the Keap1-Nrf2 complex facilitates degradation of Nrf2 by its ubiquitination [13], thereby maintaining the intracellular Nrf2 level. The many cysteine residues on Keap1 become oxidized when exposed to increased cellular oxidants, and this alteration accelerates the dissociation of the Keap1/Nrf2 complex and allows Nrf2 translocation into the nucleus $[14,15]$. Once imported into the nucleus, Nrf2 binds small Maf proteins via the leucine zipper dimerization domain, and the complexes coordinately bind to antioxidant response elements (AREs) to upregulate the expression of numerous antioxidant proteins [16]. AREs are known as enhancers and are located in the promoter region of antioxidant genes encoding a multitude of cardioprotective proteins such as quinone oxidoreductase 1 (NQ01), catalase, and heme oxygenase 1 (HO-1) [17]. Heme oxygenase 1 (HO-1) which is also called HMOX1, is a crucial defense enzyme against cellular oxidant-induced injury. HO-1 exerts cardioprotection by producing biliverdin/bilirubin [18]. HO-1 overexpression may protect the heart from I/R-induced oxidative stress and apoptosis [18].

Mitogen-activated protein kinases (MAPKs) could phosphorylate serine and tyrosine residues of proteins belonging to the protein kinase family. C-Jun $\mathrm{N}$-terminal kinase (JNK) is related to oxidative stress, which seems to be critical in mediating intracellular stress. A growing number of known ROS can activate JNK signaling, which can contribute to the development of ischemia-reperfusion injury and raise the incidence of aging-related chronic diseases [19-21].

Ginseng, the root of Panax ginseng, is a widely known traditional Chinese medicine which has been used as a tonic to enhance vitality for thousands of years [22]. Ginsenosides are regarded as one of the major pharmacologically active components of ginseng, of which ginsenoside $\operatorname{Rg} 1$ ( $\operatorname{Rg} 1$, structure shown in Fig. 1A) is the pivotal bioactive ingredient responsible for its beneficial pharmaceutical effects. Recently, accumulating evidence has demonstrated that Rg1 exhibits significant cardioprotective activities against I/R injury through numerous mechanisms, primarily attributed to the inhibition of cell apoptosis and resistance to oxidative stress [23].

\section{KARGER}


Li et al.: Ginsenoside Rg1 Ameliorates Cardiomyocytes Injury via Activating Nrf2/HO-1 and Inhibiting JNK

The purpose of the present study was to deepen the understanding of potential mechanisms whereby $\operatorname{Rg} 1$ has benefits on cardiomyocytes. Therefore, we investigated the cardioprotective role of Rg1 against oxidative stress involving activation of the Nrf2/HO-1 signaling pathway and certain protein kinases. In the present study, a well-established rat cardiomyocyte cell line was subjected to hypoxia/reoxygenation (H/R) injury, which simulated myocardial I/R injury.

\section{Materials and Methods}

\section{Reagents and chemicals}

Ginsenoside Rg1, molecular formula $\mathrm{C}_{42} \mathrm{H}_{72} \mathrm{O}_{14}$ and molecular weight 801.01, was purchased from Shanghai Woka Biotechnology Development ( $>98 \%$ purity; Shanghai, China). In certain experiments, cells were exposed to $40 \mu \mathrm{M}$ PD98059, an inhibitor of p-ERK1/2;30 $\mu \mathrm{M}$ SB203580, an inhibitor of p-P38; or $30 \mu \mathrm{M}$ SP600125, an inhibitor of p-JNK for $30 \mathrm{~min}$ before Rg1 pretreatment. These inhibitors and zinc protoporphyrin (ZnPP-IX, a HO-1 inhibitor) were obtained from Sigma-Aldrich Chemical Co. (St. Louis, MO, USA). Dihydro-CDDO-trifluoroethyl amide (Dh404) was purchased from Reata Pharmaceuticals (Irving, TX, USA). Dulbecco's Modified Eagle's Medium (DMEM) and other cell culture supplies were purchased from Gibco BRL (Grand Island, NY, USA). The cell counting kit-8 (CCK-8) assay was from Dojindo (Kyushu, Japan). Mouse antibodies against GAPDH, tubulin and $\beta$-actin were from Santa Cruz Biotechnology (Santa Cruz, CA, USA). Horseradish peroxidase labeled goat anti-mouse and anti-rabbit antibodies were also from Santa Cruz Biotechnology. Nrf2 and HO-1 antibodies were purchased from Abcam (Cambridge, UK). All phosphorylation and total kinase antibodies were from Cell Signaling Technology (Danvers, MA, USA). Rabbit anti-rat antibodies to B-cell lymphoma 2 (Bcl-2), B-cell lymphoma 2-associated X protein (Bax), cleaved caspase-3 (CC3), and cleaved caspase-7 (CC7) were also from Cell Signaling Technology. All materials for sodium dodecyl sulfate-polyacrylamide gel electrophoresis were from Bio-Rad Laboratories (Hercules, CA, USA). Assay kits for detection of lactate dehydrogenase (LDH), malondialdehyde (MDA), superoxide dismutase (SOD), glutathione peroxidase (GSH-Px), and glutathione (GSH) were obtained from Nanjing Jiancheng Bioengineering Institute (Nanjing, China). The annexin V-FITC apoptosis detection kit was from Becton Dickinson (Franklin Lakes, NJ, USA). 2',7'-Dichlorofluorescein diacetate (DCFH-DA) and JC-1 stain were purchased from Beyotime Biotechnology (Shanghai, China).

\section{Cell culture and treatment}

The rat $\mathrm{H} 9 \mathrm{c} 2$ cell line was purchased from the Cell Bank of the Chinese Academy of Sciences (Shanghai, China). The cells were cultivated in Dulbecco's modified Eagle's medium (DMEM) supplemented with $10 \%$ fetal bovine serum and 1\% (v/v) penicillin/streptomycin (Gibco, Grand Island, NY, USA) at $37^{\circ} \mathrm{C}$ in a $5 \% \mathrm{CO}_{2}$ atmosphere. We deprived $\mathrm{H} 9 \mathrm{c} 2$ cells of oxygen and glucose in the absence of serum followed by reoxygenation with glucose and serum to simulate myocardial $\mathrm{H} / \mathrm{R}$ injury in vitro. The cells were cultured with glucose-free DMEM without serum and subjected to a hypoxic environment of $1 \% \mathrm{O}_{2}, 94 \% \mathrm{~N}_{2}$ and $5 \%$ $\mathrm{CO}_{2}$ in modular gas chambers at $37^{\circ} \mathrm{C}$ for $24 \mathrm{~h}$. Then the cells were removed from the incubator chamber and cultivated in a glucose-containing culture medium with serum for $2 \mathrm{~h}$ (recovery period) in a $21 \% \mathrm{O}_{2}, 5 \%$ $\mathrm{CO}_{2}$ and $74 \% \mathrm{~N}_{2}$ incubator at $37^{\circ} \mathrm{C}$. Cells were pretreated with or without ginsenoside $\mathrm{Rg} 1 . \mathrm{Rg} 1$ was added before hypoxia and maintained for the whole hypoxia $(\mathrm{H})$ and reoxygenation $(\mathrm{R})$ period. In subsequent experiments, the cells were incubated at a proper density (mostly at $70 \%$ to $80 \%$ confluence) depending on the experimental design.

\section{Cell viability, proliferation assay and morphological examination}

Cell viability and proliferation was respectively evaluated using the cell counting kit-8 solution (CCK8) assay (Dojindo, Japan) and Bromo-2'-deoxyuridine (BrdU) Kit (Genmed Scientifics Inc, Shanghai, China). Briefly, H9c2 cells were collected and seeded at a density of $1 \times 10^{4}$ cells/well in 96-well plates for CCK8 assay. After various treatments, cells were incubated with $10 \mu \mathrm{l} \mathrm{CCK-8} \mathrm{solution} \mathrm{for} 1 \mathrm{~h}$ following the manufacturer's specifications.The data was assessed by measuring the optical density (OD) at $450 \mathrm{~nm}$ using a microplate reader (BioTek, Winooski, VT, USA). For BrdU assays, H9c2 cells were incubated with BrdU for six hours before tested. Morphological changes of $\mathrm{H} 9 \mathrm{c} 2$ cardiomyocytes were evaluated under a microscope (Leica, Wetzlar, Germany). All experiments were conducted in triplicate. 


\section{Cellular Physiology Cell Physiol Biochem 2017;44:21-37

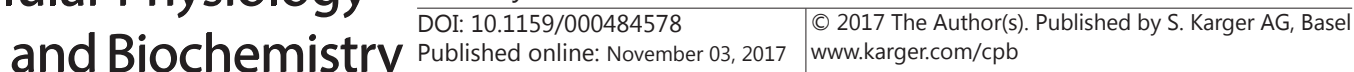

Li et al.: Ginsenoside Rg1 Ameliorates Cardiomyocytes Injury via Activating Nrf2/HO-1 and Inhibiting JNK

\section{LDH activity assay}

After pretreatment with or without Rg1 for $12 \mathrm{~h}, \mathrm{H} 9 \mathrm{c} 2$ cells were exposed to H/R, and then Rg1 treatment was maintained for the whole duration of $\mathrm{H}+\mathrm{R}$. The supernatant and cell lysates were collected, and mass LDH leakage was measured using the LDH detection kit from Nanjing Jiancheng Bioengineering Institute according to the manufacturer's directions.

\section{TUNEL assay}

H9c2 cells were seeded on glass coverslips and exposed to various treatments. Cell apoptosis was observed with the TUNEL assay kit (Roche, Basel, Switzerland) following the manufacturer's instructions. The number of TUNEL-positive (green-stained) nuclei was counted under a fluorescence microscope (Olympus, Tokyo, Japan). The apoptotic rate was then expressed as the relative percentage of TUNELpositive nuclei to the total number of cell nuclei.

\section{Annexin V-FITC/PI apoptosis assay}

Cell apoptosis was measured by an annexin V-FACS apoptosis detection kit (Becton Dickinson) according to the manufacturer's instructions. In brief, after treatment, cells were washed twice with phosphate-buffered saline (PBS) and incubated in $300 \mu \mathrm{l} 1 \mathrm{X}$ binding buffer containing $5 \mu \mathrm{l}$ annexin V-FITC for $10 \mathrm{~min}$ and then resuspended with propidium iodide in the dark for $5 \mathrm{~min}$ at $25^{\circ} \mathrm{C}$. The stained cells (containing 200, 000 cells/sample) were analyzed using an FC 500 flow cytometer (Beckman Coulter, Brea, CA, USA) within $1 \mathrm{~h}$ according to the manufacturer's protocol.

\section{ROS assay}

The production of intracellular ROS was tested using DCFH-DA as the tag based on the manufacturer's instructions. In short, H9c2 cells were cultivated on glass cover slips in 24-well plates for $24 \mathrm{~h}$. After treatment, cells were washed with PBS and then incubated with $10 \mu \mathrm{M}$ DCFH-DA in serum-free medium at $37^{\circ} \mathrm{C}$ for $30 \mathrm{~min}$ in the dark and then observed using a fluorescence microscope (Leica). Cells were collected and resuspended in the flushing fluid at approximately $1 \times 10^{6}$ cells $/ \mathrm{ml}$. After incubation with DCFH-DA, the cells were analyzed by the flow cytometer using a $488 \mathrm{~nm}$ excitation filter and a $525 \mathrm{~nm}$ emission filter.

\section{Measurement of mitochondrial membrane potential (MMP)}

JC-1 was used for evaluating the MMP. In brief, H9c2 cells were cultured on glass cover slips in 24-well plates for $24 \mathrm{~h}$. After treatment, cells were incubated with JC-1 for $20 \mathrm{~min}$ in the dark and then washed twice with JC-1 dyeing buffer. The cells dyed with JC-1 were assessed using a fluorescence microscope (Leica). Furthermore, a Synergy H4 hybrid fluorescence microplate reader (BioTek) was used to quantify changes in the MMP. Cells were cultured on glass cover slips in 96-well plates for $24 \mathrm{~h}$. After incubation with JC-1, the cells were analyzed using the fluorescence microplate reader using $490 \mathrm{~nm}$ excitation and $530 \mathrm{~nm}$ emission and using $525 \mathrm{~nm}$ excitation and $590 \mathrm{~nm}$ emission.

\section{Examination of MDA and SOD, GSH-Px and GSH levels}

H9c2 cells were cultured in 96-well plates at $10^{4}$ cells per well. After various treatments, the supernatant and the cells were respectively harvested to measure the MDA, as well as the SOD, GSH-Px and glutathione (GSH) levels with relevant detection kits per the manufacturer's instructions (Nanjing Jiancheng Bioengineering Institute, Nanjing, China).

\section{Caspase-3 activity assays}

The caspase- 3 activity was analyzed according to the instructions from the manufacturer (Beyotime Biotechnology). In short, H9c2 cardiomyocytes exposed to different treatments were lysed in lysis buffer for $15 \mathrm{~min}$ on ice. Subsequently, $50 \mu \mathrm{l}$ lysis buffer containing $40 \mu \mathrm{l}$ detection buffer was added to every sample, and $10 \mu \mathrm{l}$ of the substrate, $2 \mathrm{mM}$ Ac-DEVD-pNA, was added to the sample. After incubation for $2 \mathrm{~h}$ at $37^{\circ} \mathrm{C}$, the optical density (OD) at $405 \mathrm{~nm}$ was measured by a whole wavelength enzyme microplate reader (BioTek).

\section{Transient siRNA transfection}

To investigate siRNA interference, cells were cultivated in 6-well plates for $24 \mathrm{~h}$ and transfected with Nrf2-specific siRNA (20 nM) or specific con-siRNA using the Lipofectamine 2000 reagent (Invitrogen, Carlsbad, CA, USA) following the manufacturer's directions. After transfection for approximately 24h, H9c2 
Li et al.: Ginsenoside Rg1 Ameliorates Cardiomyocytes Injury via Activating Nrf2/HO-1 and Inhibiting JNK

cardiomyocytes were exposed to H/R injury after incubation with or without treatment with Rg1. ConsiRNA was used to assess the inhibition of Nrf2-specific siRNA.

\section{Immunofluorescence assay}

Immunofluorescence detection was used to ascertain the expression of cellular HO-1. H9c2 cells were grown on glass cover slips in 24-well plates for $24 \mathrm{~h}$ and then fixed with 4\% paraformaldehyde for 15 min, washed three times with PBS, incubated with 1\% Triton X-100 for 15 min and then with blocking buffer for $30 \mathrm{~min}$ at room temperature. After that, the cells were incubated with antibodies to HO-1 at a 1:200 dilution at $4^{\circ} \mathrm{C}$ overnight. Subsequently, the cells were washed and incubated for $1 \mathrm{~h}$ at room temperature with Cy3conjugated anti-rabbit IgG at a 1:500 dilution. Cover slips were mounted on the slides, and images of the tagged cells were viewed using a fluorescence microscope (Olympus).

\section{Western blotting}

Cultivated H9c2 cells were collected, washed twice with PBS, and lysed with cell lysis buffer including $1 \%$ phenylmethylsulfonyl fluoride. Total and nuclear proteins of the cell lysates were respectively extracted by protein extraction kits following the manufacturer's protocol (Beyotime Institute of Biotechnology, Shanghai, China). The concentration of protein was measured using a BCA kit (Beyotime Institute of Biotechnology). Protein fractions were separated by $6 \%$ or $12 \%$ SDS-polyacrylamide gel electrophoresis, and then blotted onto polyvinylidene difluoride (PVDF) membranes (Millipore Corporation, Billerica, MA, USA) in Tris-glycine buffer at $300 \mathrm{~mA}$ with an electroblotting apparatus. The PVDF membranes were blocked with $5 \%(\mathrm{w} / \mathrm{v}$ ) skim milk powder dissolved in Tris buffer containing $0.1 \%(\mathrm{v} / \mathrm{v}$ ) Tween 20 (TBST) for $2 \mathrm{~h}$ at room temperature. Subsequently, membranes were incubated overnight at $4{ }^{\circ} \mathrm{C}$ with primary antibodies against lamin B1, glyceraldehyde 3-phosphate dehydrogenase (GAPDH), tubulin, $\beta$-actin, HO-1, Nrf2, Bax, Bcl2, cleaved caspase-3, cleaved caspase-7, JNK, or p-JNK at 1:1000 dilution and washed three times with TBST. Then the membranes were incubated with horseradish peroxidase-conjugated secondary antibodies to rabbit and mouse IgG for $1 \mathrm{~h}$. After washing three times with TBST, protein expression signals were visualized by Image Lab software (Bio-Rad) after exposing the membranes to enhanced chemiluminescence solution (Millipore Corporation), with the signals normalized to GAPDH, tubulin, $\beta$-actin or lamin B1.

cDNA synthesis and quantitative real-time PCR

Total RNA samples from the cultured cardiomyocytes described above were separated using RNAiso plus reagent (TaKaRa Bio, Shiga, Japan) following the manufacturer's instructions. Total RNA ( $1 \mu \mathrm{g}$ ) was reversetranscribed using an RNA RT-PCR Kit (TaKaRa Bio), and the synthesized cDNA was used as a quantitative real-time PCR template. A series of HO-1, Nrf2 and GAPDH primers were selected by Primer Premier 5.0 software (Palo Alto, CA, USA). The sequences of the primers were: HO-1, CAGAGTTTCTTCGCCAGAGG (sense) and TGAGTGTGAGGACCC ATCG (antisense); Nrf2, ATATTCCCAGCCACGTTGAG (sense) and AACTTGCT CCATGTCCTGCT (antisense); GAPDH (internal control), GACATGCCGCCTGGA GAAAC (sense) and AGCCCAGGATGCCCTTTAGT (antisense). The levels of gene expression were evaluated by quantitative real-time PCR with an ABI PRISM 7500 Sequence Detector (Applied Biosystems, Foster City, CA, USA) following the manufacturer's instructions. SYBR Premix EX Taq sets (TaKaRa Bio) were used. All genes were amplified under identical conditions. The target gene expression level relative to the endogenous control gene (GAPDH) was calculated by the comparative Ct method formula: $2^{-\Delta \Delta \mathrm{Ct}}$.

\section{Statistical analysis}

Results were presented as means \pm SD from three independent experiments. The average value of all experiments was standardized to the control group values and used for statistical analysis. Between-group comparisons were conducted by Student's $t$-test. Statistical comparisons among different groups were determined by one-way analysis of variance followed by the least significant difference (LSD) test using SPSS software 19.0 (SPSS Inc, Chicago, IL, USA). Differences were deemed to be statistically significant when $\mathrm{P}<0.05$.

\section{Results}

Ginsenoside Rg1 attenuated H/R-induced H9c2 cell damage

The structure of Rg1 is shown in Fig. 1A. We first studied the effect of Rg1 on H9c2 cell viability and proliferation. As presented in Fig. 1B and 1E, there was no apparent change in KARGER 
Fig. 1. Protective effect of $\operatorname{Rg} 1$ on H/R-induced cytotoxicity in $\mathrm{H} 9 \mathrm{c} 2$ cells. (A) Chemical structure of $\operatorname{Rg} 1$. (B) H9c2 cells were treated with the indicated concentrations of Rg1 for $12 \mathrm{~h}$, and cell viability was analyzed by CCK-8 assay. (C) H9c2 cells were pretreated with various concentrations of Rg1 $(10,20,40$ and 60 $\mu \mathrm{M})$ for $12 \mathrm{~h}$, followed by $24 \mathrm{~h}$ of hypoxia without serum or glucose, then $2 \mathrm{~h}$ of reoxygenation in DMEM medium containing glucose and serum. Rg1 treatment maintained the course of hypoxia and reoxygenation. Cell viability was tested by CCK-8 assay. (D) Rg1 treatment decreased the H/R-induced $\mathrm{LDH}$ release in H9c2 cells. (E) Rg1 treatment had no effects on cell proliferation evaluated by Brdu assay.

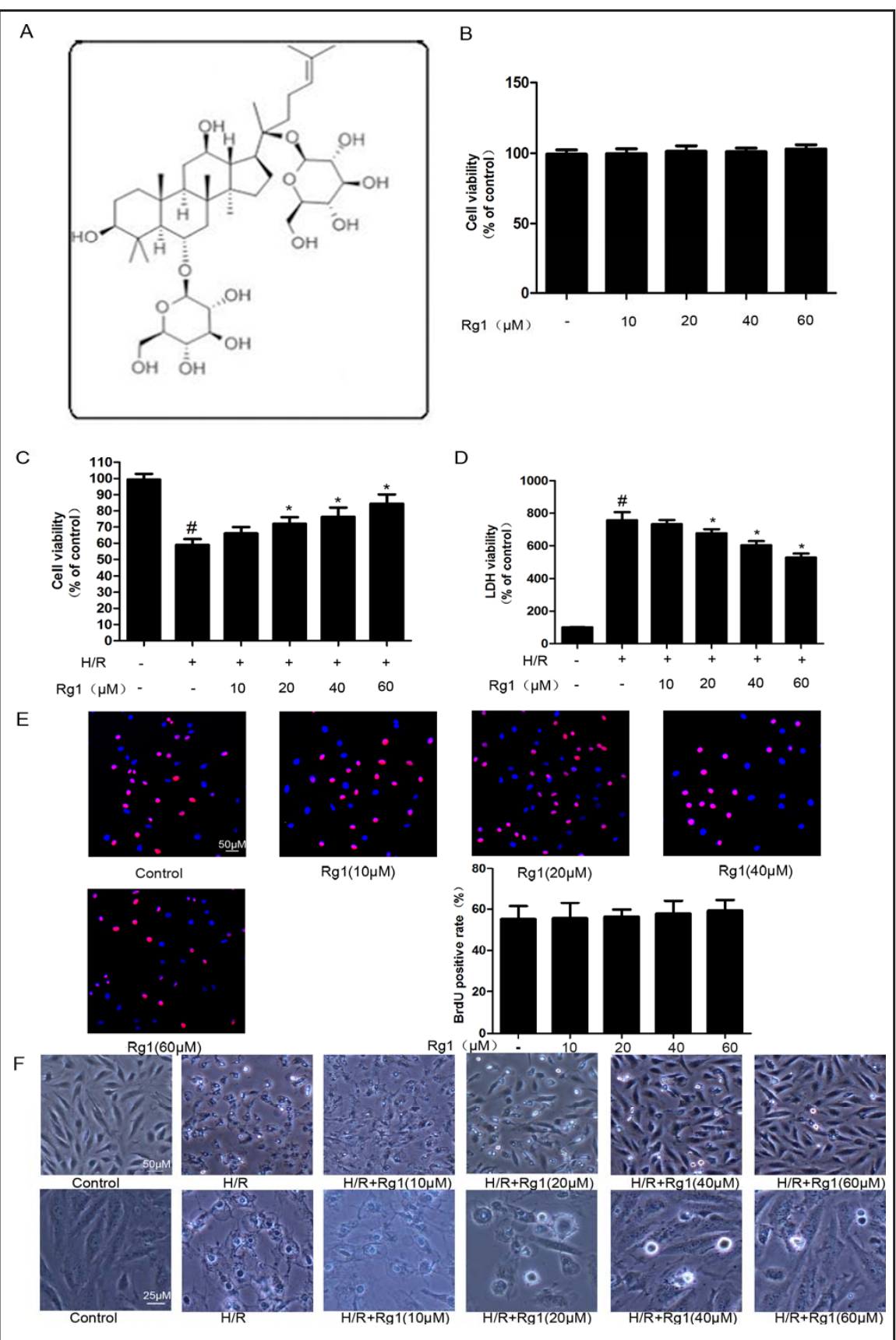

(F) Rg1 treatment reversed H/R-induced morphological changes of H9C2 cells (low and high magnification). The values are expressed as the means \pm SD of three independent experiments. $\# \mathrm{P}<0.05$ vs. the control group and $* \mathrm{P}<0.05$ vs. the H/R group.

the viability and proliferation of H9c2 cells treated with 10-60 $\mathrm{MM}$ Rg1 for $12 \mathrm{~h}$. To evaluate whether ginsenoside Rg1 protects H9c2 cells from H/R-induced damage, cells were exposed to hypoxia for $24 \mathrm{~h}$ and then reoxygenated for $2 \mathrm{~h}$. Under $\mathrm{H} / \mathrm{R}$ conditions, the cell viability decreased to approximately 59\% based on CCK-8 assays. LDH leakage is considered a marker of cell injury due to plasma membrane disruption, which is significantly increased after $\mathrm{H} / \mathrm{R}$ treatment. In contrast, Rg1 dose-dependently improved cell viability and ameliorated the increased LDH release (Fig. 1C and 1D). In addition, we observed morphological changes of 
Fig. 2. Inhibitory effect of Rg1 on H/R-induced H9c2 cell apoptosis. H9c2 cells were pretreated with the indicated concentrations of Rg1 (10, 20, 40 and 60 $\mu \mathrm{M}$ ) for $12 \mathrm{~h}$, followed by $24 \mathrm{~h}$ of hypoxia and $2 \mathrm{~h}$ of reoxygenation with Rg1. (A) TUNELstained, DAPI-stained and merged micrographs of both TUNELstained and DAPIstained cells exposed to $\mathrm{H} / \mathrm{R}$ at different concentrations of $\mathrm{Rg} 1$. The quantification of TUNEL positive cells are shown in C.(B) Apoptotic cells were stained with annexin V-FITC and propidium iodide (PI) for flow cytometry. The raw flow cytometry figures are shown in B, and the apoptosis rates are shown in D. The results are the means \pm SD of three independent experiments. $\quad \# \mathrm{P}<0.05$ vs. the control group and ${ }^{*} \mathrm{P}<0.05$ vs. the $\mathrm{H} / \mathrm{R}$ group.

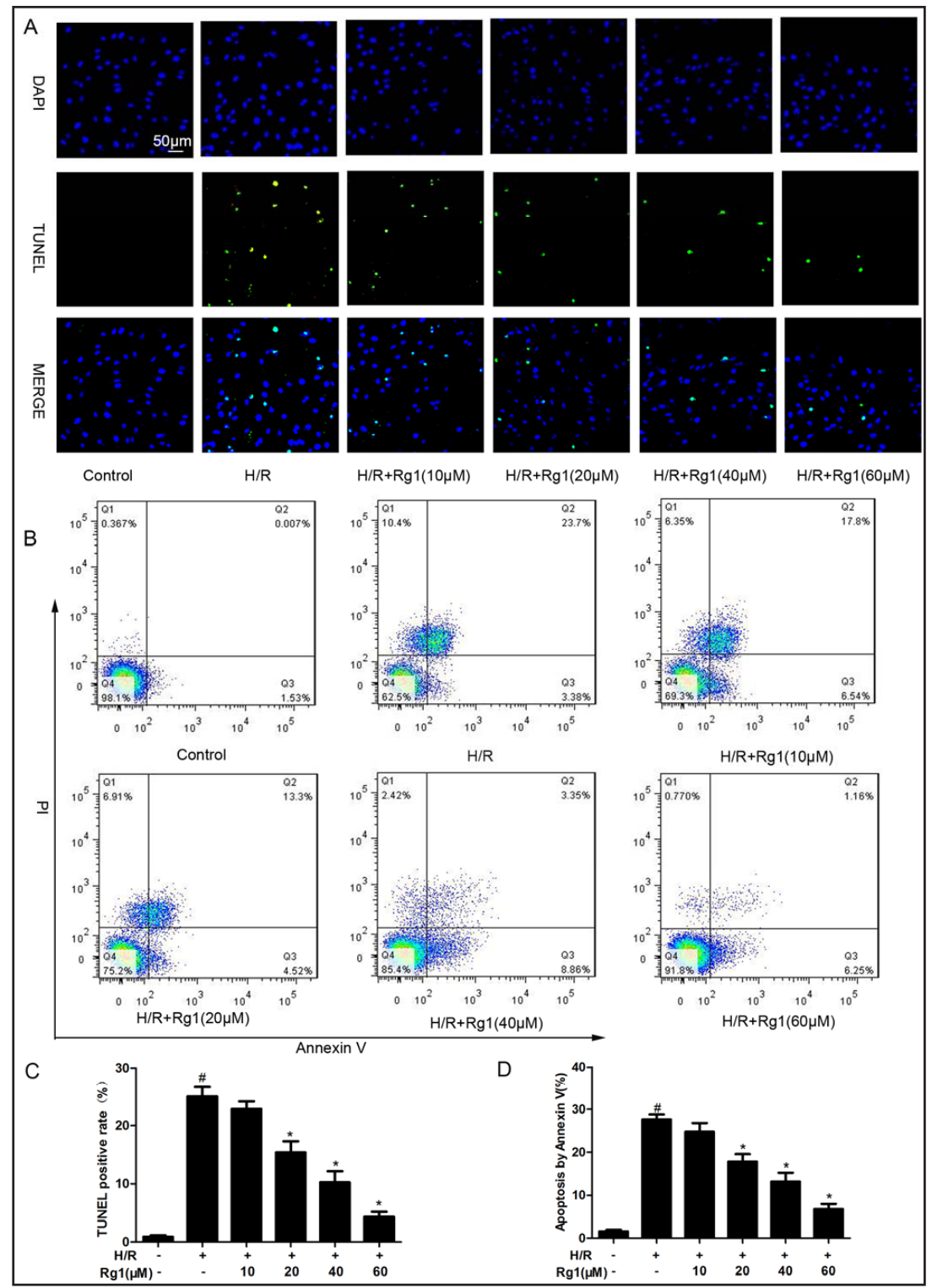

H9c2 cells by light microscopy for different experimental groups. As presented in Fig. 1F, the control group seemed to have densely packed membranes and a normal cell morphology. Nevertheless, the cells exposed to $\mathrm{H} / \mathrm{R}$ treatment had incompletely packed membranes and showed features of shrinkage. Rg1 treatment mitigated these abnormal morphological features in a dose-dependent manner.

\section{Ginsenoside Rg1 protected $H 9 c 2$ cells from $H / R$-induced apoptosis}

H9c2 cell apoptosis was detected by two assays: a TUNEL test and flow cytometry. As shown in Fig. 2A and 2C, Rg1 treatment significantly reduced the number of TUNEL-positive cardiomyocytes (stained green) subjected to H/R injury. The inhibitory effect of Rg1 on H9c2 cell apoptosis was supported by a flow cytometry assay (Fig. 2B). After exposure to H/R, the apoptotic rate of H9c2 cells increased, an effect that was largely restrained by Rg1 treatment (Fig. 2D).

Ginsenoside Rg1 alleviated the expression of proteins involved in apoptosis

To investigate whether Rg1 can modulate the expression of apoptosis proteins, the expression of Bax and Bcl-2 was assessed by western blotting. As shown in Fig. 3A, the 


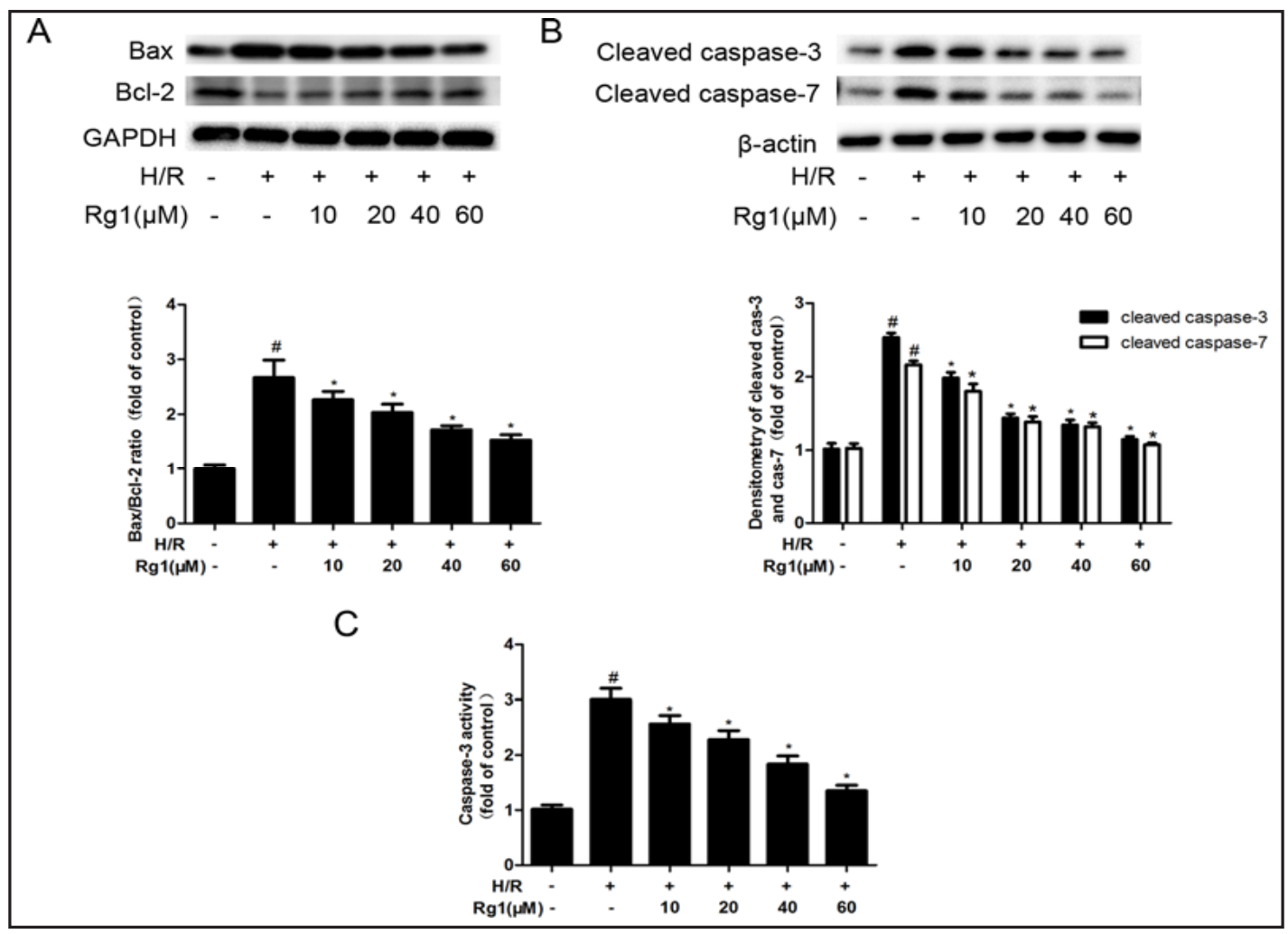

Fig. 3. Inhibition of $\operatorname{Rg} 1$ on the expression of pro-apoptotic proteins and caspase-3 activity. H9c2 cells were pretreated with the indicated concentrations of $\operatorname{Rg} 1(10,20,40$ and $60 \mu \mathrm{M})$ for $12 \mathrm{~h}$, followed by $24 \mathrm{~h}$ of hypoxia and $2 \mathrm{~h}$ of reoxygenation with Rg1. (A) Rg1 prevented H/R-induced Bax expression and reversed the reduction in Bcl-2. (B) Rg1 mitigated H/R-induced cleaved caspase-3 and cleaved caspase-7 expression. (C) Rg1 decreased H/R-induced caspase-3 activity. The expression of Bax, Bcl-2, cleaved caspase-3 and cleaved caspase-7 was evaluated by western blotting. GAPDH and $\beta$-actin respectively served as internal controls. Caspase- 3 activity was monitored by optical density (OD) assays. The results are the means \pm SD of three independent experiments. ${ }^{*} \mathrm{P}<0.05$ vs. the control group and ${ }^{*} \mathrm{P}<0.05$ vs. the $\mathrm{H} / \mathrm{R}$ group.

level of Bax significantly increased after exposure to H/R, whereas the level of Bcl-2 was evidently reduced, which caused a high Bax/Bcl-2 ratio and implied that H/R-initiated apoptosis may be mediated by the mitochondrial apoptosis pathway in H9c2 cells. However, administration of Rg1 generally attenuated the changes in Bax and Bcl-2 in a concentrationdependent manner (Fig. 3A). Caspases play a pivotal role in the initiation of the apoptotic cascade in various biological processes. We observed that the levels of cleaved caspase- 3 and cleaved caspase-7 increased in the H/R group compared with the control group. The administration of $\operatorname{Rg} 1$ substantially reversed the change (Fig. 3B). $\operatorname{Rg} 1$ also inhibited the activity of caspase-3 in a dose-dependent manner after exposure to H/R (Fig. 3C). All these measurements clarified that the cardioprotective effect of Rg1 against H/R-induced injury might be ascribed to apoptosis inhibition.

Ginsenoside Rg1 reduced H/R-induced ROS generation and the decline in MMP and increased the concentration of intracellular antioxidant enzymes

The DCFH-DA fluorescence assay and flow cytometry analysis were conducted to examine the level of cellular ROS, which fluoresced green. H/R treatment elevated the ROS level in H9c2 cells, while the administration of Rg1 reduced the H/R-induced intracellular ROS generation in a dose-dependent manner (Fig. 4A and 4C). A decline in the MMP can trigger a cascade of apoptotic processes. To evaluate whether H/R-induced apoptosis and Rg1 treatment were related to the MMP pathway in H9c2 cells, MMP was estimated using 
Li et al.: Ginsenoside Rg1 Ameliorates Cardiomyocytes Injury via Activating Nrf2/HO-1 and Inhibiting JNK

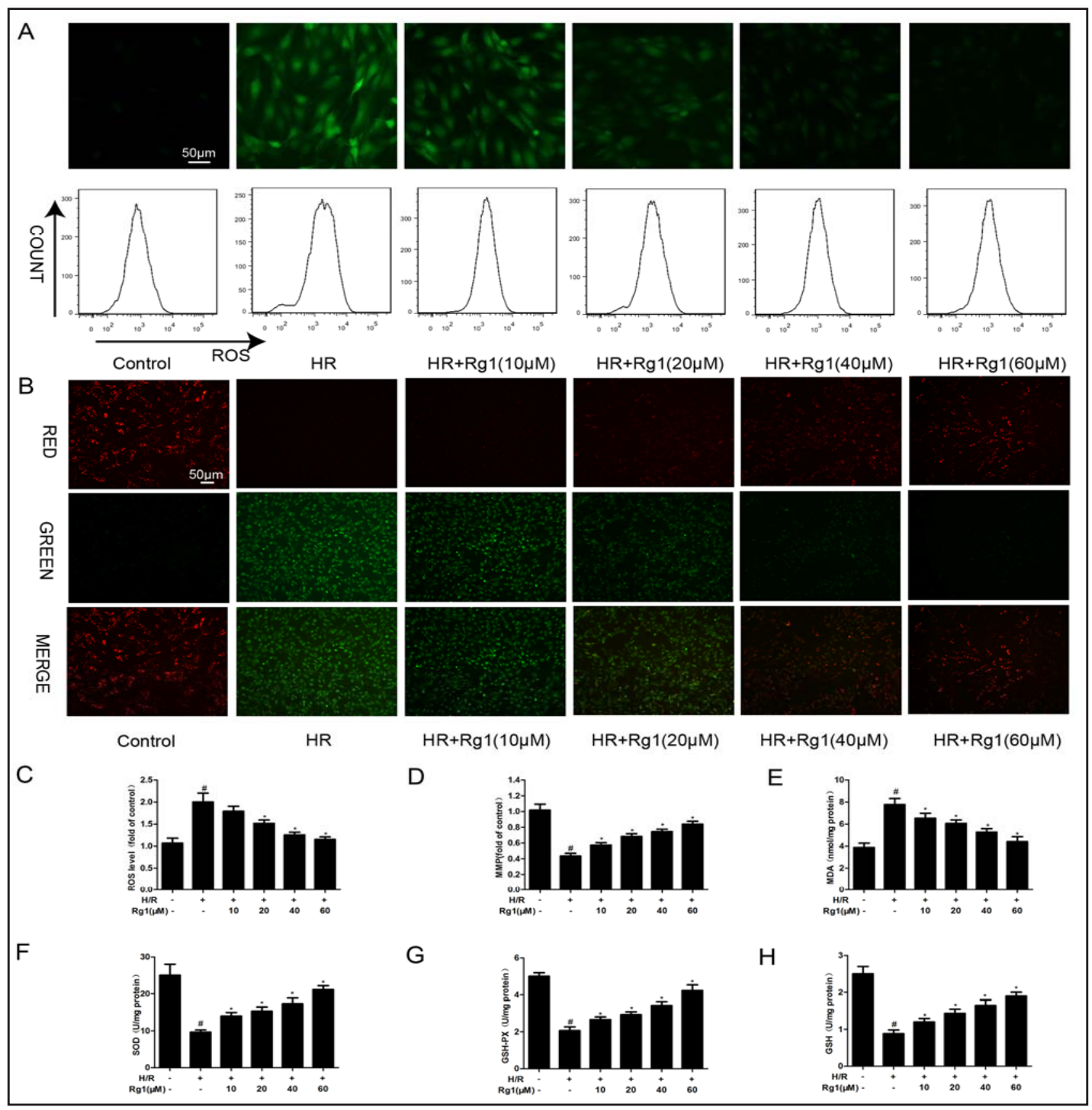

Fig. 4. Effects of Rg1 on intracellular ROS production and MMP and antioxidant enzyme activity. H9c2 cells preincubated with or without Rg1 (10-60 $\mu \mathrm{M})$ for $12 \mathrm{~h}$, then exposed to H/R with Rg1 treatment at different concentrations. (A) ROS levels were determined by a fluorescence microscope and analyzed by flow cytometry using DCFH-DA. (B) After incubation, H9c2 cells were stained with JC-1. The membrane potential was observed by a fluorescence microscope and quantified by a fluorescence microplate reader. (C) Quantitative analysis of ROS staining. (D) Quantitative analysis of JC-1 staining. (E) Rg1 treatment lowered the level of MDA in H9c2 cells exposed to H/R. (F-H) Rg1 treatment prevented the H/R-induced decrease of SOD, GSH-Px, and GSH activity in H9c2 cells. The results are the means \pm SD of three independent experiments. $\# \mathrm{P}<0.05$ vs. the control group and $* \mathrm{P}<0.05$ vs. the $\mathrm{H} / \mathrm{R}$ group.

JC-1 staining. As shown in Fig. 4B, normal mitochondria exhibited red fluorescence after JC-1 staining in H9c2 cells. H/R exposure raised the amount of green fluorescence, which suggested that MMP decreased, lowering the red/green fluorescence ratio, which was closely related to apoptosis. In contrast, Rg1 treatment largely enhanced the red/green fluorescence ratio, a sign of an improved MMP (Fig. 4D). To monitor the intracellular antioxidant capacity of H9c2 cells, we detected the levels of MDA, and the activity of SOD, GSH-Px, and GSH. MDA is one of the most important products of membrane lipid oxidation. H9c2 cells subjected to $\mathrm{H} / \mathrm{R}$ showed a dramatic increase in MDA levels that was inhibited by Rg1 treatment (Fig. $4 \mathrm{E}$ ). In addition, $\mathrm{H} / \mathrm{R}$ exposure brought about a decrease in the levels of some endogenous

\section{KARGER}




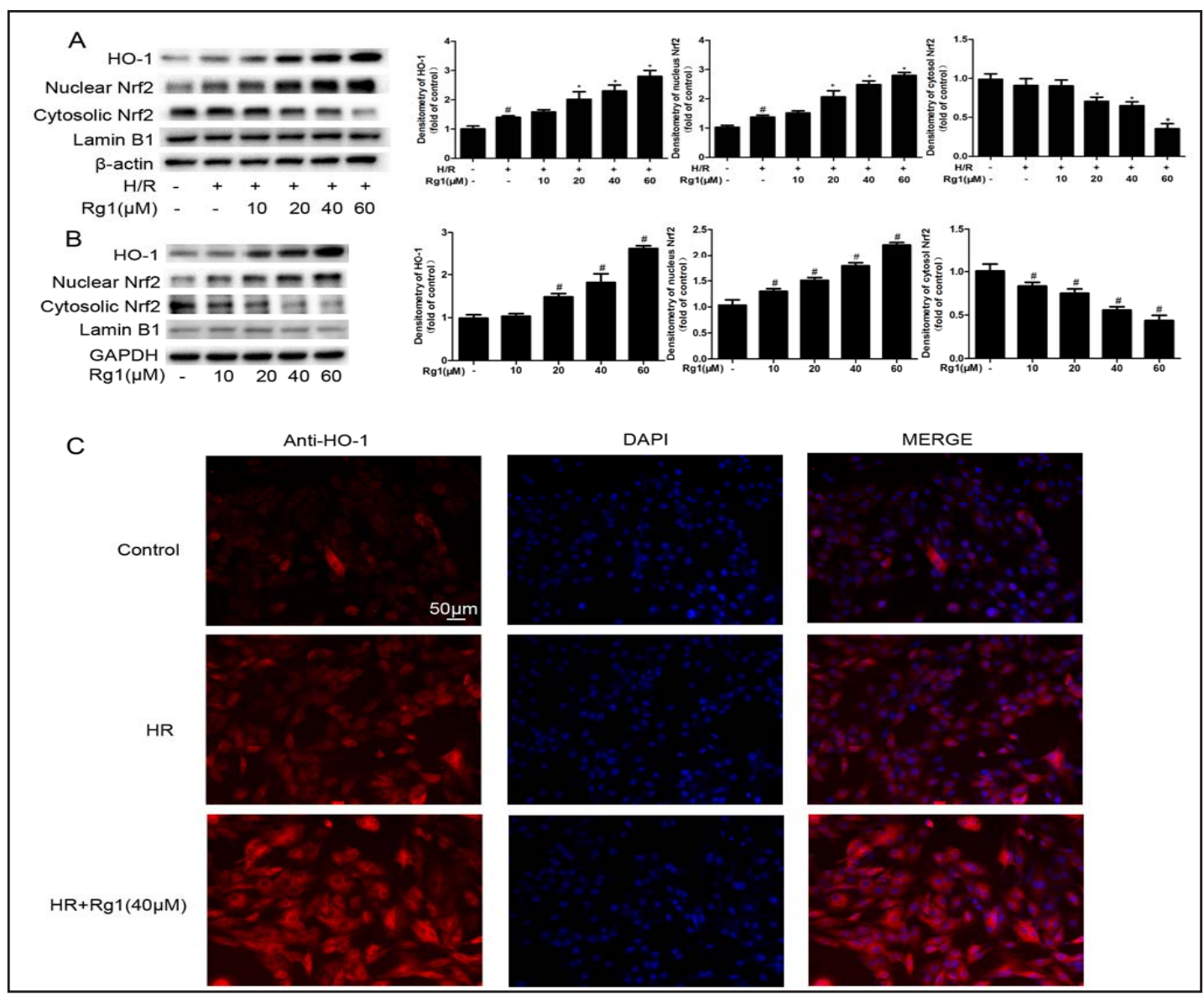

Fig. 5. Effects of Rg1 on Nrf2/HO-1 signaling. (A) H9c2 cells were pretreated with $\operatorname{Rg} 1$ (10, 20, 40 and 60 $\mu \mathrm{M}$ ) for $12 \mathrm{~h}$, and then exposed to H/R with Rg1 treatment at different concentrations. Cytosolic and nuclear proteins were prepared for western blotting. (B) H9c2 cells were pretreated with $\operatorname{Rg} 1$ (10, 20, 40 and 60 $\mu \mathrm{M}$ ) for $12 \mathrm{~h}$. The effects of Rg1 on Nrf2 nuclear translocation and the expression of HO-1 were observed by western blotting. (C) H9c2 cells were pretreated with $40 \mu \mathrm{M} \mathrm{Rg} 1$ for $12 \mathrm{~h}$ and then exposed to H/R with Rg1 treatment. Immunofluorescence assays were performed to detect the effects of Rg1 and H/R on the expression of HO- 1 . The results are the means \pm SD of three independent experiments. $\# \mathrm{P}<0.05$ vs. the control group and ${ }^{*} \mathrm{P}<0.05$ vs. the $\mathrm{H} / \mathrm{R}$ group.

antioxidative enzymes (SOD, GSH-Px, and GSH). However, Rg1 treatment substantially increased the level of SOD, GSH-Px, and GSH in a dose-dependent manner (Fig. 4F-4H). These results demonstrated that Rg1 could defend against cell oxidative stress injury by strengthening the endogenous antioxidant supply.

\section{Ginsenoside Rg1 activated $\mathrm{Nrf2/HO}-1$ in $\mathrm{H} 9 \mathrm{c} 2$ cells}

$\mathrm{Nrf} 2$ and its target gene HO-1 are significant regulators responsive to various stresses. They act to confer resistance to multifarious cellular oxidative stresses. Our study demonstrated that Rg1 suppressed ROS production induced by H/R. We next investigated whether this effect was due to modulation of the Nrf2/HO-1 pathway. As shown in Fig. $5 \mathrm{~A}, \mathrm{H} / \mathrm{R}$ induced a modest increase in the expression of HO-1 protein and the nuclear translocation of Nrf2 in H9c2 cells. Compared with the H/R group, Rg1 treatment enhanced nuclear Nrf2 and HO-1 expression in H9c2 cells. Moreover, Rg1 treatment alone also could elevated the expression of nuclear Nrf2 and HO-1 protein in a dose-dependent manner (Fig. 5B). Immunofluorescence detection confirmed that Rg1 treatment resulted in an apparent increase in the expression of HO-1 (Fig. 5C).

\section{KARGER}




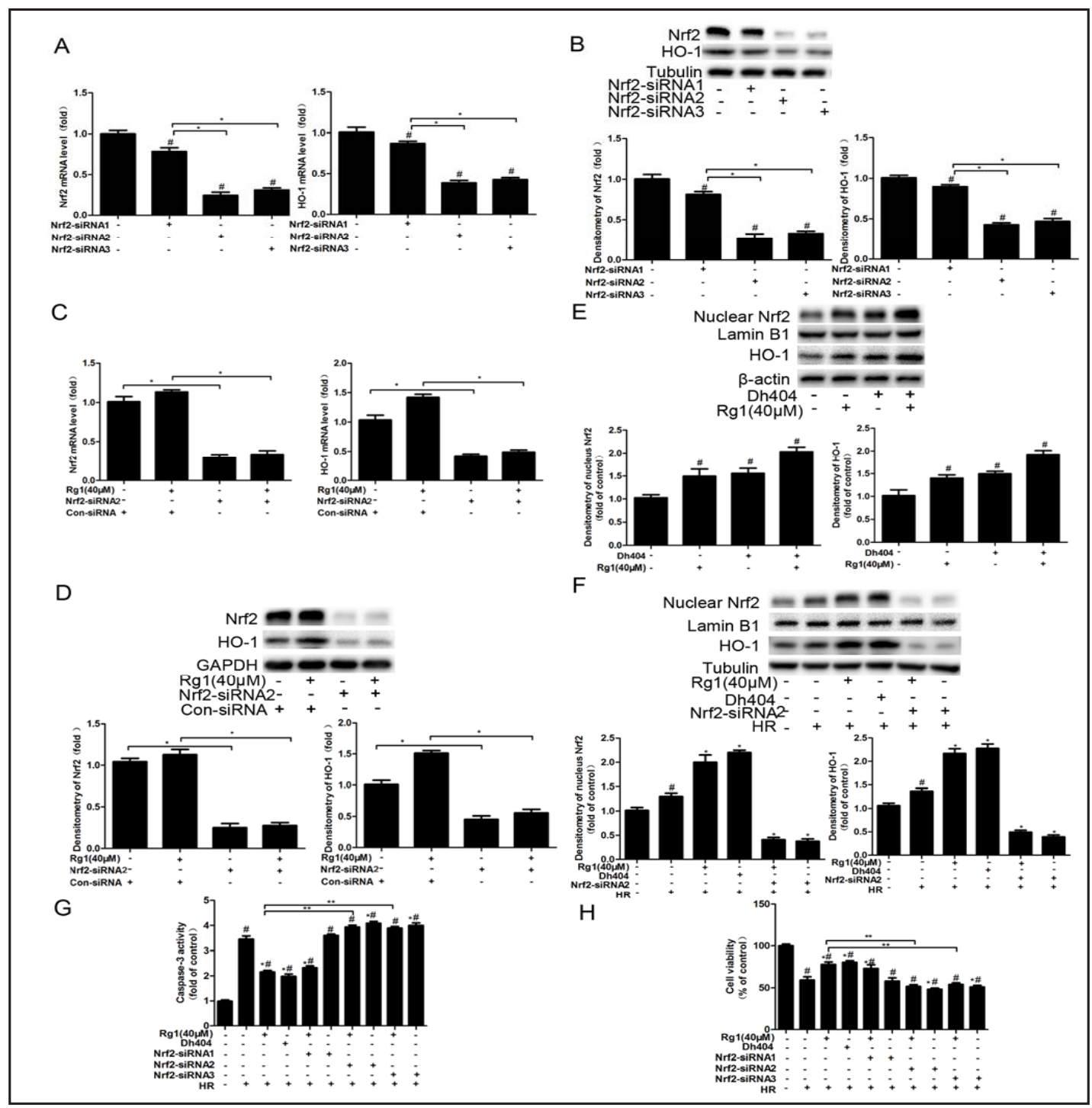

Fig. 6. Effects of Rg1 on nuclear accumulation of Nrf2, HO-1 expression, and cardioprotection after Nrf2siRNA transfection. (A and B) H9c2 cells were treated with different Nrf2-specific siRNA. The mRNA and protein levels of Nrf2 and HO-1 were measured by real-time PCR and western blotting. (C and D) H9c2 cells were treated with either an Nrf2-specific siRNA2 or a control siRNA, and then stimulated with $40 \mu \mathrm{M}$ Rg1 for $12 \mathrm{~h}$. At $24 \mathrm{~h}$ after Nrf2-siRNA2 transfection, the mRNA and protein levels of Nrf2 and HO-1 were measured by real-time PCR and western blotting. ${ }^{*} \mathrm{P}<0.05$ vs. con-siRNA group. (E) H9c2 cells were stimulated with $40 \mu \mathrm{M} \operatorname{Rg} 1$ and $0.3 \mu \mathrm{M}$ Dh404 for $12 \mathrm{~h}$. Nrf2 nuclear translocation and expression of HO-1 were observed by western blotting. (F) H9c2 cells were treated with either Nrf2-specific siRNA2 or a control siRNA for 24 h before stimulation with $\operatorname{Rg} 1(40 \mu \mathrm{M})$ for $12 \mathrm{~h}$, and then exposed to H/R with $40 \mu \mathrm{M}$ Rg1 co-incubation. Nrf2 nuclear translocation and protein expression of HO-1 were determined by western blotting. Caspase-3 activity $(G)$ and cell viability $(H)$ were measured using a microplate reader. Data are means \pm SD of three independent experiments. ${ }^{\#} \mathrm{P}<0.05$ vs. the control group, ${ }^{*} \mathrm{P}<0.05$ vs. the $\mathrm{H} / \mathrm{R}$ group and ${ }^{* *} \mathrm{P}<0.05$ vs. the H/R plus Rg1 group.

\section{Nrf2-siRNA transfection abolished the protective effect of Rg1 in H9c2 cells}

To evaluate whether Nrf2 had a significant role in Rg1 defense against oxidative damage, H9c2 cells were transiently transfected with Nrf2-siRNA to inhibit Nrf2 expression, revealing that Nrf2 in H9c2 cells could be significantly knocked down by siRNA2 and siRNA3 (Fig. 6A 
Li et al.: Ginsenoside Rg1 Ameliorates Cardiomyocytes Injury via Activating Nrf2/HO-1 and Inhibiting JNK

Fig. 7. Effects of ZnPP-IX on Rg 1 - me di ated cardioprotection. H9c2 cells were pretreated with Rg1 $(40 \mu \mathrm{M})$ with or without ZnPP-IX $(10 \mu \mathrm{M})$ for $12 \mathrm{~h}$, and then exposed to $\mathrm{H} / \mathrm{R}$ with $40 \mu \mathrm{M} \quad \mathrm{Rg} 1$ trea tmen t with or without ZnPP-IX $(10 \mu \mathrm{M})$. (A) Representative western blots of Bax and Bcl-2 are shown. The B a x / B c l - 2 ratio was calculated. (B)

Flow cytometry was used to determine the apoptotic ratio of H9c2 cardiomyocytes. (C) Quantitative analysis of the apoptosis rates. (D) Representative results for ROS production after different types of stimulation were analyzed by flow cytometry. (E) The fluorescence intensity of ROS was computed relative to that of the control group. Data are means \pm SD of three independent experiments. ${ }^{\mathrm{P}}<0.05$ vs. the control group, ${ }^{*} \mathrm{P}<0.05$ vs. the $\mathrm{H} / \mathrm{R}$ group and ${ }^{* *} \mathrm{P}<0.05$ vs. the $\mathrm{H} / \mathrm{R}+\mathrm{Rg} 1$ group.

and 6B). The expression of HO-1 was inhibited in H9c2 cells transfected with Nrf2-siRNA2 and Nrf2-siRNA3 (Fig. 6A-6D). Furthermore, as demonstrated in Fig. 6E, Rg1 treatment alone induced a considerable increase in nuclear Nrf2 and HO-1 expression, in accordance with Dh404 being a Nrf2 activator. However, Nrf2 interference eliminated the Rg1-induced nuclear Nrf2 and HO-1 upregulation in H9c2 cells with or without H/R exposure (Fig. 6D and 6F). Our results also supported Rg1 treatment alleviating the increase in caspase- 3 activity and improving cell viability, in sharp contrast with the H/R group. However, Rg1 failed to ameliorate the increased caspase- 3 activity or enhance cell viability after Nrf2 inhibition accompanying H/R exposure (Fig. 6G and 6H). Obviously, the cardioprotective effect of Rg1 was inhibited in $\mathrm{H} 9 \mathrm{c} 2$ cells transiently transfected with Nrf2-siRNA2 and Nrf2-siRNA3. These data indicated that Nrf2 signaling played a critical role in the protective effect of Rg1 on H9c2 cells exposed to H/R injury.

\section{ZnPP-IX negated the protective effect of $\mathrm{Rg} 1$}

Western blotting revealed that H9c2 cardiomyocytes exposed to H/R had a significantly increased Bax/Bcl-2 ratio compared with the control group, while Rg1 decreased the Bax/ Bcl-2 ratio compared with the H/R group. This effect was partially reversed by ZnPP-IX (Fig. 7A). Flow cytometry showed that $\mathrm{H} / \mathrm{R}$ gave rise to an increase in cell apoptosis in H9c2 cells compared with the control group, whereas apoptosis declined distinctly after Rg1 treatment. The inhibitory effect of $\mathrm{Rg} 1$ on apoptosis was moderated by ZnPP-IX (Fig. 7B and C). These 
Fig. 8. Effects of P38, E R K $1 / 2$, and JNK inhibitors on H9c2 cells exposed to H/R. After i n c u b a tion with SB2 03580 $\left(\begin{array}{ll}30 & \mu \mathrm{M}\end{array}\right)$, P D 98059 $(40 \mu \mathrm{M})$ or SP 600125 $\left(\begin{array}{ll}30 & \mu \mathrm{M}\end{array}\right)$ for $30 \mathrm{~min}$, H9c2 cells were then exposed to H/R. H9c2 cells were pretreated with $40 \mu \mathrm{M}$ Rg1 for 12 $\mathrm{h}$ and then exposed to $\mathrm{H} / \mathrm{R}$ in the presence of $40 \quad \mu \mathrm{M}$ Rg1. (A) Immunoblot analysis for

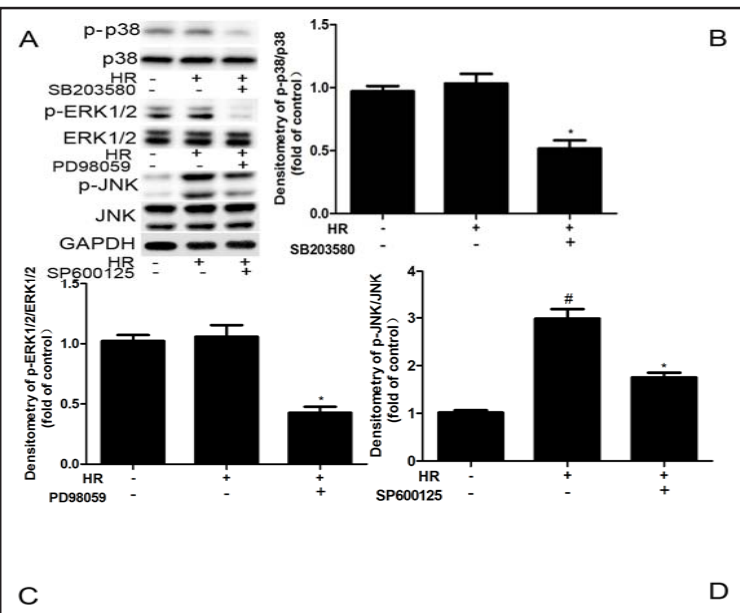
B $c$
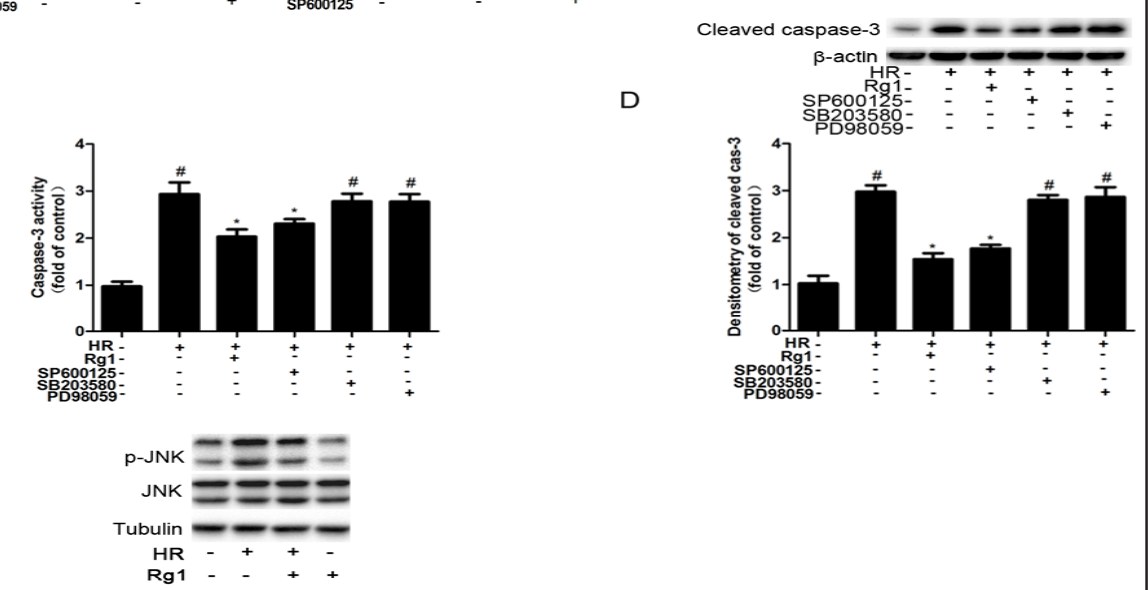

$E$

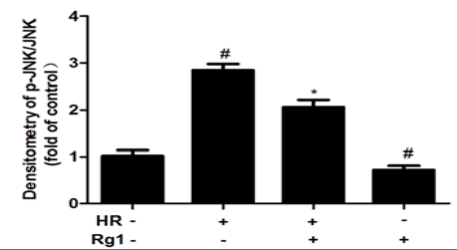

phosphorylation of p38, ERK1/2, and JNK in cells exposed to HR after incubation with SB203580, PD98059, and SP600125. (B) Cell viability was determined by a CCK-8 assay. (C) Caspase-3 activity was measured by optical density (OD) assays using a microplate reader. (D) Cleaved caspase-3 was assessed by western blotting. (E) Immunoblot analysis of phosphorylation of JNK in $\mathrm{H} 9 \mathrm{c} 2$ cells after different treatments. The results are means \pm SD of three independent experiments. $\# \mathrm{P}<0.05$ vs. the control group and ${ }^{*} \mathrm{P}<0.05$ vs. the $\mathrm{H} / \mathrm{R}$ group.

results illustrated that Rg1 reduced the ROS level in the H/R group, while the use of ZnPP-IX mitigated the protective effect of Rg1 (Fig. 7D and E).

Ginsenoside Rg1 inhibited activation of the JNK pathway in H/R-induced H9c2 cell toxicity

The chemical inhibitors of p38 (SB203580), ERK1/2 (PD98059), and JNK (SP600125) significantly inhibited the phosphorylation of p38, ERK1/2, and JNK (Fig. 8A).To investigate the influence of inhibitors on H/R-induced damage to H9c2 cells, cell viability was assessed after treatment with them. H/R exposure could obviously reduce H9c2 cell viability. Cell viability was not dramatically altered by PD98059 or SB203580 treatment, but Rg1 and SP600125 treatment elevated cell viability (Fig. 8B). As indicated in Fig. 8C and D, PD98059 and SB203580 pretreatment failed to inhibit the upregulation of caspase- 3 activity and cleaved caspase-3 expression induced by H/R exposure in H9c2 cells, yet Rg1 and SP600125 pretreatment ameliorated the effect. To confirm these observations, we investigated the expression of total JNK and p-JNK. The level of p-JNK increased in the H/R exposure group 
compared with the control group in H9c2 cells, and Rg1 treatment inhibited the elevation of p-JNK (Fig. 8E). These results suggested that Rg1 attenuated H/R-induced H9c2 cell damage partly by inhibiting activation of the JNK pathway.

\section{Discussion}

Cardiomyocyte I/R injury causes cell apoptosis, which is mostly ascribed to a series of oxidative bursts and a cascade of inflammatory responses. A considerable number of potential strategies and pharmacological agents are reported to alleviate reperfusion injury. However, these strategies and agents, in terms of their clinical outcomes, have been unsatisfactory [24]. It is of vital importance to develop new pharmacological strategies for ameliorating reperfusion injury.

Ginsenoside Rg1 is a chief biologically active component in ginseng [25], which exhibits multiple beneficial effects, including anti-aging properties [26] and neuroprotection [27]. Accumulated evidence suggests that $\operatorname{Rg} 1$ has a particularly strong cardioprotective effect on cardiomyocytes, primarily resulting from its potent antioxidant properties $[28,29]$. However, the mechanism by which Rg1 protects against I/R-induced myocardial injury remains unclear. In the study, we exposed H9c2 cells to culture medium without serum, glucose or glutamate, and then placed them in a modular hypoxia chamber for $24 \mathrm{~h}$, followed by $2 \mathrm{~h}$ of reoxygenation under normal atmospheric conditions. $\operatorname{Rg} 1$ at 10-60 $\mu \mathrm{M}$ concentration-dependently increased cell survival following H/R injury. Rg1 also decreased LDH leakage to the culture buffer. Furthermore, Rg1 could reverse morphological changes in cardiomyocytes subjected to H/R injury. We ascertained that Rg1 mitigated the apoptotic changes in H9c2 cells induced by H/R. Bax can promote apoptosis, while Bcl-2 antagonizes apoptosis. The Bax/Bcl-2 ratio determines the destiny of many cells, including the survival of cardiomyocytes. Bax or Bcl-2 may control the mitochondrial permeability transition and aggravate the release of cytochrome $c$, which eventually triggers the activation of caspase- 3 and caspase-7, bringing about apoptosis [30, 31]. In our study, administration of $\operatorname{Rg} 1$ reduced the ratio of $\mathrm{Bax} / \mathrm{Bcl}-2$ in a dose-dependent manner by downregulating Bax and upregulating Bcl-2. Caspases play key roles throughout the apoptotic progression, which regulate apoptosis through cleavage of various specific substrates. Our results showed that Rg1 alleviated the H/R-induced augmentation of the expression of cleaved caspase- 3 and caspase- 7 proteins and caspase- 3 activity. These observations clarified that the antiapoptotic effects of Rg1 could be partially due to the inactivation of caspases that are closely associated with the regulation of Bax and Bcl-2 expression in H9c2 cells exposed to H/R. Cell H/R injury is the complex processes which involve various signaling pathways and molecules. Rg1 could partially suppressed the cell injury by antioxidative function.So cell viability, LDH leakage and apoptosis do not revert to control levels.

Excessive ROS under H/R states is intimately associated with cell apoptosis by damaging various molecules that affect key biological pathways [32]. Therefore, the elimination of numerous ROS by antioxidants may be a critical way to restrain ROS-induced cell injury. Cellular antioxidants scavenge the majority of free radicals and attenuate a variety of injuries originating from oxidative stress [33]. The present study demonstrated that $\mathrm{H} / \mathrm{R}$ exposure markedly accelerates ROS production in H9c2 cardiomyocytes, hence elevating the levels of MDA, which is a toxic end-product of lipid peroxidation and indicates oxidative stress. The administration of ginsenoside Rg1 reduced H/R-induced ROS and MDA production and raised the levels of endogenous antioxidant enzymes, including total SOD, GSH-Px and GSH. These results confirmed that $\mathrm{Rg} 1$ might inhibit H/R-induced H9c2 cell injury by increasing the concentration of intracellular antioxidants. Previous reports showed similar results of Rg1 exerting protective effects by antioxidative function in lung injury [34]. Our study found that MMP decreased following exposure to $H / R$, which ultimately resulted in the accumulation of ROS and fairly apparent dysfunction in mitochondria. We determined that $\operatorname{Rg} 1$ elevated MMP, inhibited mitochondrial dysfunction, and prevented oxidative stress, principally by reducing ROS generation stemming from increased concentrations of antioxidants. 
Nrf2 serves as a crucial regulator in response to oxidative stress and activation of endogenous antioxidant enzymes. Under physiological states, Nrf2 is bound to negative regulator Keap1 and is oriented toward the cytoplasm. On exposure to oxidative stress, Nrf2 dissociates from Keap1 and is then translocated into the nucleus, where it induces the expression of the HO-1 gene that functions as an antioxidative modulator [35]. HO-1 is also known as HSP32, which has a pivotal function in reaction to oxidative stress [36]. It is a ratelimiting enzyme in the transition of heme into biliverdin [37]. Previous evidence supported that the expression of HO-1 was modulated by the Nrf2 signaling pathway [38]. Our study demonstrated for the first time that the $\mathrm{Nrf} 2 / \mathrm{HO}-1$ signaling pathway participated in the protection of $\operatorname{Rg} 1$ against heart I/R injury. It also clarified that the nuclear translocation of Nrf2 and HO-1 upregulation in H9c2 cells were moderately induced following H/R injury. Nevertheless, Rg1 plus H/R injury significantly enhanced Nrf2 translocation and the expression of HO-1 protein. Thus, we exposed H9c2 cells to different concentrations of Rg1 without H/R exposure and discovered that Rg1 promoted the activation of the Nrf2 signaling pathway in a dose-dependent manner. Finally, immunofluorescence results revealed that Rg1 treatment led to a dramatic increase in cytoplasmic HO-1 staining, suggesting that Rg1 induces HO-1 upregulation following H/R injury.

Nrf2-siRNA transfection was implemented to further explore the function of Nrf2 in the substantially protective effect of Rg1 against H/R induced H9c2 injury. Our study determined that transient transfection with Nrf2-siRNA2 and Nrf2-siRNA3 can significantly inhibit the mRNA and protein levels of Nrf2 and HO-1 in H9c2 cells. Dh404 is a synthetic triterpenoid compound that is a Nrf2 activator. Dh404 enhances Nrf2 nuclear translocation by inhibiting the ubiquitination and proteasome degradation of Nrf2 after binding to Cys151 of Keap-1 [39]. Our study found that both Rg1 and Dh404 could accelerate Nrf2 nuclear translocation and HO-1 overexpression, which identified Rg1 as a novel Nrf2 activator. However, Nrf2siRNA2 transfection treatment abolished Rg1-induced HO-1 overexpression with or without exposure to H/R. These results indicated that activation of the Nrf2 signaling pathway after Rg1 treatment was responsible for the upregulation of HO-1 enzyme. Furthermore, we found that Nrf2 inhibition abolished the protective effect of Rg1 against H/R-induced H9c2 injury. In the present study, Rg1 decreased the caspase-3 activity and improved cell viability of H9c2 cells exposed to H/R. However, Nrf2-siRNA2 and Nrf2-siRNA3 transfection reversed these effects. These results suggested that Rg1 protected against H/R-induced H9c2 cell oxidative stress damage, principally by activation of Nrf2 signaling.

ZnPP-IX competitively inhibits HO-1 activity resulting from its similarity to heme in the porphyrin ring structure. Apoptosis induced by oxidative stress contributes to the pathological physiological process of $H / R$ injury [40]. In H9c2 cells exposed to $H / R$, mass production of ROS damages the integrity of the mitochondrial membrane, which activates the mitochondrial apoptosis pathway. Along with causing a mitochondrial permeability transition, expression of Bcl-2 is suppressed and Bax is enhanced, leading to apoptotic cascades. Western blotting showed that Rg1 lowered the Bax/ Bcl-2 ratio compared with the H/R group, and that the antiapoptotic effect of Rg1 was negated by ZnPP-IX. The results of flow cytometric analysis suggested that Rg1 lowered the apoptotic rate and decreased ROS production of the H9c2 cells subjected to $\mathrm{H} / \mathrm{R}$, but these effects were markedly blocked by ZnPP-IX. Therefore, we concluded that Rg1 inhibited H/R-induced H9c2 cardiomyocyte apoptosis, at least partially through upregulation of HO-1.

Another finding of our study concerned the inhibitory effect of $\operatorname{Rg} 1$ on p-JNK activation. SP600125, a specific competitive inhibitor of JNK, improved cell viability and attenuated caspase-3 activity and the expression of cleaved caspase-3 in H9c2 cells compared with the H/R group. We found that Rg1 markedly downregulated the levels of p-JNK. These results disclosed that JNK activation might be involved in $\mathrm{H} 9 \mathrm{c} 2$ cell apoptosis, providing new insight into Rg1 cardioprotection. However, the mechanisms of Rg1cardioprotection during H/R need to be further investigated in vivo.

In summary, this study demonstrated that Rg1 can protect H9c2 cells from H/R-induced apoptosis by alleviating oxidative stress injury, which depended largely on subsequent 
Li et al.: Ginsenoside Rg1 Ameliorates Cardiomyocytes Injury via Activating Nrf2/HO-1 and Inhibiting JNK

Nrf2 nuclear translocation and upregulation of HO-1. Collectively, our results suggest that Rg1 could be a candidate drug for patients with acute myocardial infarction to prevent cardiomyocyte apoptosis initiated by I/R. We expect these results to contribute to the development of new drugs for reperfusion treatment.

\section{Acknowledgements}

This work was supported by the Three-Year Action Plan (2014-2016) of Shanghai Municipality for further acceleration of the development of Chinese Medicine (no. ZY3CCCX-3-3040). The funders had no role in study design, data collection and analysis, or in the decision to prepare or publish the manuscript.

\section{Disclosure statement}

The authors report no conflicts of interest.

\section{References}

1 Murphy E, Steenbergen C: Mechanisms underlying acute protection from cardiac ischemia-reperfusion injury. Physiol Rev 2008;88:581-609.

2 Hausenloy DJ, Yellon DM: Myocardial ischemia-reperfusion injury: a neglected therapeutic target. J Clin Invest 2013;123:92-100.

-3 Kawaguchi M, Takahashi M, Hata T, Kashima Y, Usui F, Morimoto H, Izawa A, Takahashi Y, Masumoto J, Koyama J, Hongo M, Noda T, Nakayama J, Sagara J, Taniguchi S, Ikeda U: Inflammasome activation of cardiac fibroblasts is essential for myocardial ischemia/reperfusion injury. Circulation 2011;123:594-604.

-4 Ovize M, Baxter GF, Di Lisa F, Ferdinandy P, Garcia-Dorado D, Hausenloy DJ, Heusch G, Vinten-Johansen J, Yellon DM, Schulz R: Postconditioning and protection from reperfusion injury: where do we stand? Position paper from the Working Group of Cellular Biology of the Heart of the European Society of Cardiology. Cardiovasc Res 2010;87:406-423.

-5 McCord JM: Oxygen-derived free radicals in postischemic tissue injury. N Engl J Med 1985;312:159-163.

-6 Frangogiannis NG, Smith CW, Entman ML: The inflammatory response in myocardial infarction. Cardiovasc Res 2002;53:31-47.

7 Eltzschig HK, Eckle T: Ischemia and reperfusion--from mechanism to translation. Nat Med 2011;17:13911401.

8 Molavi B, Mehta JL: Oxidative stress in cardiovascular disease: molecular basis of its deleterious effects, its detection, and therapeutic considerations. Curr Opin Cardiol 2004;19:488-493.

-9 Goswami SK, Maulik N, Das DK: Ischemia-reperfusion and cardioprotection: a delicate balance between reactive oxygen species generation and redox homeostasis. Ann Med 2007;39:275-289.

10 Cominacini L, Mozzini C, Garbin U, Pasini A, Stranieri C, Solani E, Vallerio P, Tinelli IA, Fratta Pasini A: Endoplasmic reticulum stress and Nrf2 signaling in cardiovascular diseases. Free Radic Biol Med 2015;88:233-242.

11 Kaspar JW, Niture SK, Jaiswal AK: Nrf2:INrf2 (Keap1) signaling in oxidative stress. Free Radic Biol Med 2009;47:1304-1309.

12 Wakabayashi N, Slocum SL, Skoko JJ, Shin S, Kensler TW: When NRF2 talks, who's listening? Antioxid Redox Signal 2010;13:1649-1663.

13 Kansanen E, Kuosmanen SM, Leinonen H, Levonen AL: The Keap1-Nrf2 pathway: Mechanisms of activation and dysregulation in cancer. Redox Biol 2013;1:45-49.

14 Suzuki T, Yamamoto M: Molecular basis of the Keap1-Nrf2 system. Free Radic Biol Med 2015;88:93-100.

15 Itoh K, Ye P, Matsumiya T, Tanji K, Ozaki T: Emerging functional cross-talk between the Keap1-Nrf2 system and mitochondria. J Clin Biochem Nutr 2015;56:91-97.

16 Blank V: Small Maf proteins in mammalian gene control: mere dimerization partners or dynamic transcriptional regulators? J Mol Biol 2008;376:913-925. 


\section{Cellular Physiology Cell Physiol Biochem 2017;44:21-37 \begin{tabular}{l|l|l|l|l}
\hline DOI: 10.1159/000484578 & $\begin{array}{l}\text { (c) } 2017 \text { The Author(s). Published by S. Karger AG, Basel } \\
\text { www.karger.com/cpb }\end{array}$ \\
\hline and Biochemistry
\end{tabular} and Biochemistry}

Li et al.: Ginsenoside Rg1 Ameliorates Cardiomyocytes Injury via Activating Nrf2/HO-1 and Inhibiting JNK

17 Girnun GD, Domann FE, Moore SA, Robbins ME: Identification of a functional peroxisome proliferatoractivated receptor response element in the rat catalase promoter. Mol Endocrinol 2002;16:2793-2801.

18 Vulapalli SR, Chen Z, Chua BH, Wang T, Liang CS: Cardioselective overexpression of HO-1 prevents I/Rinduced cardiac dysfunction and apoptosis. Am J Physiol Heart Circ Physiol 2002;283:H688-694.

19 Lamb RE, Goldstein BJ: Modulating an oxidative-inflammatory cascade: potential new treatment strategy for improving glucose metabolism, insulin resistance, and vascular function. Int J Clin Pract 2008;62:10871095.

20 Mkaddem SB, Bens M, Vandewalle A: Differential activation of Toll-like receptor-mediated apoptosis induced by hypoxia. Oncotarget 2010;1:741-750.

-21 Sun KH, Lee HG, Smith MA, Shah K: Direct and indirect roles of cyclin-dependent kinase 5 as an upstream regulator in the c-Jun NH2-terminal kinase cascade: relevance to neurotoxic insults in Alzheimer's disease. Mol Biol Cell 2009;20:4611-4619.

22 Ellis JM, Reddy P: Effects of Panax ginseng on quality of life. Ann Pharmacother 2002;36:375-379.

23 Lee CH, Kim JH: A review on the medicinal potentials of ginseng and ginsenosides on cardiovascular diseases. J Ginseng Res 2014;38:161-166.

24 Bolli R, Becker L, Gross G, Mentzer R, Jr., Balshaw D, Lathrop DA: Myocardial protection at a crossroads: the need for translation into clinical therapy. Circ Res 2004;95:125-134.

25 Xu FT, Li HM, Zhao CY, Liang ZJ, Huang MH, Li Q, Chen YC, Chi GY: Characterization of Chondrogenic Gene Expression and Cartilage Phenotype Differentiation in Human Breast Adipose-Derived Stem Cells Promoted by Ginsenoside Rg1 In vitro. Cell Physiol Biochem 2015;37:1890-1902.

26 Zhu J, Mu X, Zeng J, Xu C, Liu J, Zhang M, Li C, Chen J, Li T, Wang Y: Ginsenoside Rg1 prevents cognitive impairment and hippocampus senescence in a rat model of D-galactose-induced aging. PLoS One 2014;9:e101291.

-27 Jiang B, Xiong Z, Yang J, Wang W, Wang Y, Hu ZL, Wang F, Chen JG: Antidepressant-like effects of ginsenoside Rg1 are due to activation of the BDNF signalling pathway and neurogenesis in the hippocampus. Br J Pharmacol 2012;166:1872-1887.

28 Zhang ZL, Fan Y, Liu ML: Ginsenoside Rg1 inhibits autophagy in H9c2 cardiomyocytes exposed to hypoxia/ reoxygenation. Mol Cell Biochem 2012;365:243-250.

29 Bao C, Wang Y, Min H, Zhang M, Du X, Han R, Liu X: Combination of ginsenoside Rg1 and bone marrow mesenchymal stem cell transplantation in the treatment of cerebral ischemia reperfusion injury in rats. Cell Physiol Biochem 2015;37:901-910.

30 Lindsten T, Zong WX, Thompson CB: Defining the role of the Bcl-2 family of proteins in the nervous system. Neuroscientist 2005;11:10-15.

-31 Kirkland RA, Franklin JL: Bax, reactive oxygen, and cytochrome c release in neuronal apoptosis. Antioxid Redox Signal 2003;5:589-596.

-32 Hensley K, Robinson KA, Gabbita SP, Salsman S, Floyd RA: Reactive oxygen species, cell signaling, and cell injury. Free Radic Biol Med 2000;28:1456-1462.

-33 Wang QD, Pernow J, Sjoquist PO, Ryden L: Pharmacological possibilities for protection against myocardial reperfusion injury. Cardiovasc Res 2002;55:25-37.

34 Shen L, Han JZ, Li C, Yue SJ, Liu Y, Qin XQ, Liu HJ, Luo ZQ: Protective effect of ginsenoside Rg1 on glutamateinduced lung injury. Acta Pharmacol Sin 2007;28:392-397.

-35 Kensler TW, Wakabayashi N, Biswal S: Cell survival responses to environmental stresses via the Keap1Nrf2-ARE pathway. Annu Rev Pharmacol Toxicol 2007;47:89-116.

-36 Li H, Gu B, Zhang Y, Lewis DF, Wang Y: Hypoxia-induced increase in soluble Flt-1 production correlates with enhanced oxidative stress in trophoblast cells from the human placenta. Placenta 2005;26:210-217.

-37 Maines MD: The heme oxygenase system: past, present, and future. Antioxid Redox Signal 2004;6:797-801.

38 Siow RC, Ishii T, Mann GE: Modulation of antioxidant gene expression by 4-hydroxynonenal: atheroprotective role of the Nrf2/ARE transcription pathway. Redox Rep 2007;12:11-15.

39 Li B, Abdalrahman A, Lai Y, Janicki JS, Ward KW, Meyer CJ, Wang XL, Tang D, Cui T: Dihydro-CDDOtrifluoroethyl amide suppresses inflammatory responses in macrophages via activation of Nrf2. Biochem Biophys Res Commun 2014;444:555-561.

-40 Scarabelli TM, Knight R, Stephanou A, Townsend P, Chen-Scarabelli C, Lawrence K, Gottlieb R, Latchman D, Narula J: Clinical implications of apoptosis in ischemic myocardium. Curr Probl Cardiol 2006;31:181-264. 